\title{
Maintenance of motility of fowl spermatozoa in vitro is prolonged by a low molecular weight factor derived from cultured chick embryo cells
}

\author{
K. Ashizawa and S. Katayama \\ Laboratory of Animal Reproduction, Faculty of Agriculture, Miyazaki University, \\ Miyazaki 889-2I, Japan
}

\begin{abstract}
Summary. Gel filtration of a conditioned medium composed of the supernatant fluid removed from a 5-day culture of skeletal muscle cells from 9-day-old chick embryos with Bio-Gel P-2 revealed one peak of motility-prolonging activity (about $0.3 \mathrm{kDa}$ ), which was not present in fresh medium. Spermatozoa incubated in this fraction of the conditioned medium maintained their motility for at least $36 \mathrm{~h}$ at $37^{\circ} \mathrm{C}$. Both the formation of lipid peroxide and the leakage of lactic dehydrogenase of spermatozoa incubated in the conditioned medium fraction were lower than those incubated in the corresponding fresh medium. Initial rate of oxygen consumption of the spermatozoa incubated in the conditioned medium fraction increased compared with that of the fresh medium fraction. These results suggest that a low molecular weight factor(s) supplied by cultured cells effectively prolongs the motility of fowl spermatozoa, and that the effect could result from inhibition of the structural damage to the sperm membrane.
\end{abstract}

Keywords: spermatozoa; motility; embryonic cells; conditioned medium; fowl

\section{Introduction}

In domestic fowl, fertilizing ability of spermatozoa stored in Ringer's solution at $41^{\circ} \mathrm{C}$, the normal body temperature of the fowl, is lost within a few hours (Schindler et al., 1955). In contrast, when fowl spermatozoa are incubated at $40-41^{\circ} \mathrm{C}$ with cultured cells prepared from the fowl oviduct, fowl kidney and skeletal muscle of a 9-day-old chick embryo their motility is maintained for 5-7 days and fertilizing ability for 2-4 days (Ashizawa et al., 1976; Ashizawa \& Nishiyama, 1977; Fujihara \& Howarth, 1980). HeLa and BHK-21 cells, which are not related to fowl cells, also prolong sperm survival (Ashizawa et al., 1982b). Such cultured cells also contribute to the maintenance of motility of some mammalian spermatozoa (Ashizawa et al., 1982b).

It has been demonstrated that the maintenance of sperm motility is inversely related to the distance between the cultured cells and spermatozoa (Ashizawa \& Nishiyama, 1978; Ashizawa et al., 1982a). Furthermore, it has been shown that cultured cells and spermatozoa are not interdependent and that it is the living cultured cells which exert a favourable effect on the maintenance of motility of spermatozoa (Ashizawa et al., 1983b). From this evidence, it was suggested that a substance(s) supplied by the living cultured cells diffused to the spermatozoa and effectively prolonged sperm motility (Ashizawa \& Nishiyama, 1978; Ashizawa et al., 1983b).

Fujihara \& Howarth (1980) reported that fluid removed from cultured cells prepared from the shell gland of the fowl oviduct contained secretory products that can prolong the motility and fertilizing ability of fowl spermatozoa stored in vitro at $41^{\circ} \mathrm{C}$. Fujihara \& Koga (1982) also indicated that secretory products from oviductal cells cultured at $41^{\circ} \mathrm{C}$ prolonged sperm motility and that the favourable constituent(s) may have a molecular weight of over $12 \mathrm{kDa}$. In contrast, 
Ashizawa et al. (1983a) suggested that the main effective factor(s) for prolonging sperm motility is a low molecular weight substance(s) $(<10 \mathrm{kDa})$. However, precise properties of the factor(s) are not well understood.

The present study investigated the factor(s) responsible for prolonging motility of fowl spermatozoa and determined some of the properties of the factor(s).

\title{
Materials and Methods
}

\begin{abstract}
Animals
Commercial White Leghorn roosters and hens (Babcock strain, Akagi Poultry Breeding Farm, Miyazaki, Japan) were used throughout the study. All birds were housed in cages and fed ad libitum on a commercial breeder diet. They were exposed to $14 \mathrm{~h}$ light per $24 \mathrm{~h}$.
\end{abstract}

\section{Preparation of test fluids}

Monolayer cultures of skeletal muscle cells of 9-day-old chick embryos were obtained by culturing cells in Eagle's Minimum Essential Medium supplemented with 5\% newborn calf serum (Grand Island Biological Co., USA) at $37^{\circ} \mathrm{C}$ in $5 \% \mathrm{CO}_{2}$ and $95 \%$ air. Cell preparations and cultures were carried out according to the method described by Ashizawa et al. (1976). After 1 day, the culture was replenished with $5 \mathrm{ml}$ of fresh medium and subsequently cultured for a further 5 days. On the sixth day, the culture medium was collected and centrifuged at $1000 \mathrm{~g}$ for $10 \mathrm{~min}$ to remove floating cells and debris. The supernatant, designated as conditioned medium was stored at $-30^{\circ} \mathrm{C}$ until use.

Fresh medium and conditioned medium were filtered with an ultrafiltration membrane (Ultrafilter P-0200, approximate exclusion size of 20000 , Advantec Co., Tokyo, Japan). The filtrate will be referred to as 'fresh medium filtrate' and 'conditioned medium filtrate', respectively. The residue was redissolved in the serum-frec fresh medium to its original volume and the fluid will be referred to as 'fresh medium-residue' and 'conditioned medium-residue', respectively. Also, the filtrate and residue were reconstituted to the original fresh medium or conditioned medium and will be referred to as 'fresh medium-mixture' and 'conditioned medium-mixture', respectively.

For gel filtration, $100 \mathrm{ml}$ of fresh medium or conditioned medium was concentrated 25 -fold by freeze drying. BioGel P-2 (Bio-Rad Laboratories, Richmond, CA, USA) was hydrated and equilibrated in $0 \cdot 15 \mathrm{~mol} \mathrm{NaCl} 1^{-1}$ with $20 \mathrm{mmol}$-TES ( $\mathrm{N}$-tris-[hydroxymethyl] methyl-2-aminoethane sulfonic acid) $1^{-1}$, adjusted to $\mathrm{pH} 7.4 \mathrm{with} 1 \mathrm{~mol} \mathrm{NaOH}$ $\mathrm{l}^{-1}$, in a $2.6 \times 56 \mathrm{~cm}$ column. The $\times 25$ concentrated fresh medium or conditioned medium ( $\left.3 \mathrm{ml}\right)$ was passed through the column at a flow rate of $50 \mathrm{ml} \mathrm{h}^{-1}$ at $4 \mathrm{C}$ and $40 \times 10 \mathrm{ml}$ samples were collected and stored at $4^{\circ} \mathrm{C}$ before assay. Osmotic pressure of each fraction was measured by freezing-point depression with a osmometer (Orion Riken Co., Ltd, Model Osmotron-5, Tokyo, Japan). Absorbance of the fraction at $280 \mathrm{~nm}$ was also measured using a doublebeam spectrophotometer (Shimadzu, Model UV-150-02, Kyoto, Japan). Estimation of molecular weight was made by comparing the retention of unknown substances on the Bio-Gel P-2 column with that of standard substances under the same conditions. The standard substances used were oxidized glutathione (GSSG), reduced glutathione (GSH), cysteine and sodium azide.

\section{Measurements of the effect of test fluids on the maintenance of motility of spermatozoa}

In the first series of experiments, $0.3 \mathrm{ml}$ of 'filtrate', 'residue' and 'mixture' of fresh medium and conditioned medium was poured into multiwell tissue culture plates ( $15 \mathrm{~mm}$ in diameter), and pooled fowl semen was added to the test fluids to reach a concentration of approximately $1 \times 10^{8}$ spermatozoa $\mathrm{ml}^{-1}$. The semen was collected as cleanly as possible from several roosters by the method of Fujihara et al. (1973). Penicillin $\mathrm{G}$ potassium (1000 units $\mathrm{ml}^{-1}$ ) and streptomycin sulfate $\left(\mathrm{I} \mathrm{mg} \mathrm{ml}^{-1}\right.$ ) were routinely added to the medium. After addition to the test fluids, the spermatozoa were incubated under the same conditions as described above for the culture of cells. After 12 and $24 \mathrm{~h}$ of incubation, sperm motility was examined at room temperature $\left(20-25^{\circ} \mathrm{C}\right)$. The evaluation of motility was carried out by observing spermatozoa from several areas (usually four or five) of each well of tissue culture plate directly from above using an inverted microscope. An arbitrary scale of six classifications of motility was used (Wheeler \& Andrews, 1943), and the maintenance of motility of spermatozoa in conditioned media was compared with those in corresponding fresh media, respectively.

In the second series of experiments, using fractionated samples with gel filtration, the duration of the maintenance of motility of spermatozoa in conditioned media was compared with those in corresponding fresh media. The assay methods were the same as described above. During the incubation period at $37^{\circ} \mathrm{C}$, motility of spermatozoa was examined every $6 \mathrm{~h}$ until they became immotile, and duration of the maintenance of motility of spermatozoa was determined. 


\section{Measurements of the effects of test fluids on the oxygen consumption, lipid peroxide production and lactate dehydrogenase leakage of spermatozoa}

In the third series of experiments, using the filtration fraction that was the most effective for the maintenance of motility of spermatozoa (fraction no. 15), the effects of conditioned medium and fresh medium on oxygen consumption, lipid peroxide production and lactic dehydrogenase (LDH) leakage of spermatozoa were compared. The oxygen consumption of spermatozoa was determined polarographically with a Clark electrode by the method of Kielley (1963) using a YSI model 53 biological oxygen monitor (Yellow Springs Instrument Co., Ohio, USA). The collected semen was washed once with $\mathrm{NaCl}$ - TES solution (see above) by centrifuging the suspension at $700 \mathrm{~g}$ for $12 \mathrm{~min}$. Immediately after the spermatozoa were washed, oxygen consumption was measured at $37^{\circ} \mathrm{C}$ for about $5 \mathrm{~min}$. Sperm concentration was estimated by correlation with optical density (Wishart \& Ross, 1985). The initial rate of oxygen consumption was expressed in terms of $\mu$ l oxygen consumption $10^{-8}$ spermatozoa $\mathrm{h}^{-1}$.

For the analysis of lipid peroxide production and LDH leakage of spermatozoa, test fluids with or without $0.5 \mathrm{mmol}$ L-ascorbic acid $1^{-1}$ and semen were incubated under the conditions described above for the sperm motility assay. After 6 and $12 \mathrm{~h}$ of incubation, malonaldehyde formed in the spermatozoa was determined by the thiobarbituric acid reaction (Barber \& Bernheim, 1967). Lactic dehydrogenase activity released from spermatozoa was estimated by the method of Wróblewski \& LaDue (1955). All data were subjected to statistical analysis using Student's $/$ test.

\section{Results}

\section{Effects of test fluids on the maintenance of motility of fowl spermatozoa}

In the residue $(>20 \mathrm{kDa})$, the motility score of spermatozoa after $24 \mathrm{~h}$ incubation in conditioned medium was slightly greater than in fresh medium, but there was no significant difference (Fig. 1). However, spermatozoa incubated in the conditioned medium filtrate $(<20 \mathrm{kDa})$ maintained their motility until $24 \mathrm{~h}$, whereas spermatozoa incubated in fresh medium filtrate lost their motility rapidly. In the mixture of filtrate and residue, the motility of spermatozoa after $24 \mathrm{~h}$ incubation in conditioned medium was significantly higher than in fresh medium $(P<0.05)$.

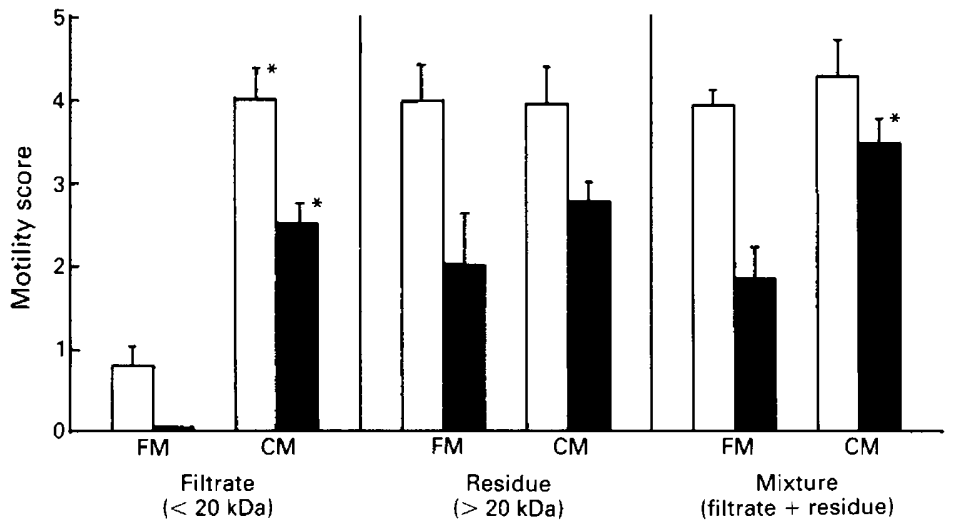

Fig. 1. Comparison of motility of fowl spermatozoa incubated in ultrafiltered fresh medium (FM) and conditioned medium (CM) for $12 \mathrm{~h} \square$ and $24 \mathrm{~h} \square$ at $37^{\circ} \mathrm{C}$. Each value represents the mean \pm SEM of five samples of spermatozoa. ${ }^{*} P<0.05$ compared with corresponding fresh media.

One peak of motility-prolonging activity from the Bio-Gel P-2 column was distinguished in the conditioned medium, but there was no such peak in the fresh medium. Spermatozoa incubated in this fraction (fraction no. 15) of the conditioned medium maintained their motility for at least $36 \mathrm{~h}$. Molecular weight standards were chromatographed under the same conditions (Fig. 3). On the basis of this standard curve, the molecular weight of the motility-prolonging fraction is approximately $0.3 \mathrm{kDa}$. 


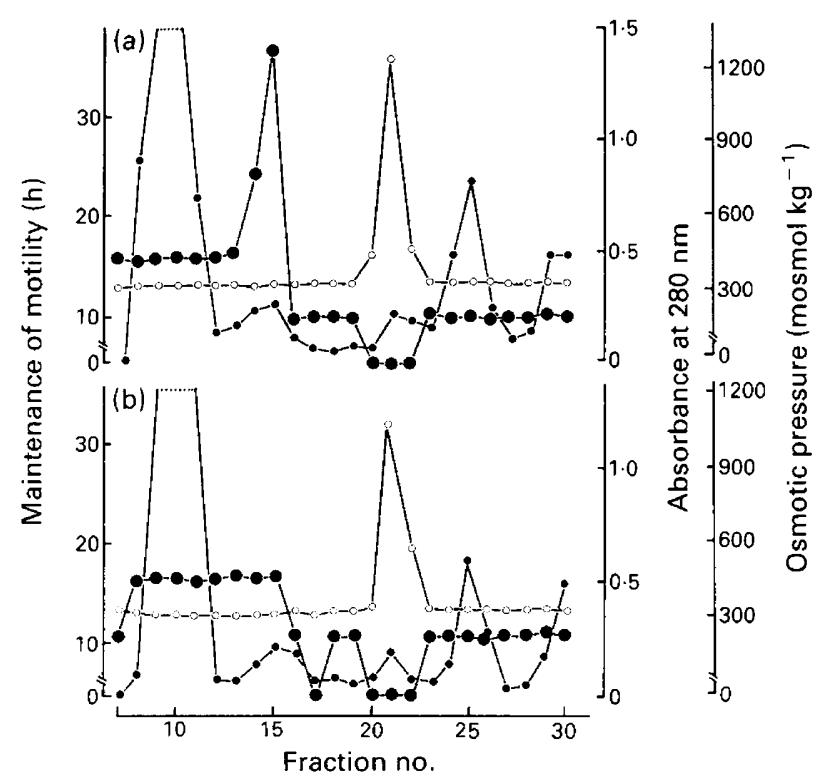

Fig. 2. Separation of motility-prolonging activity of conditioned medium prepared from cultured embryonic cells. The elution profiles represented from (a) the conditioned medium and (b) fresh medium. Osmotic pressures ( ) and absorbance at $280 \mathrm{~nm}(\cdot)$ of samples are shown with the maintenance of motility of fowl spermatozoa incubated at $37^{\circ} \mathrm{C}(\boldsymbol{\bullet})$.

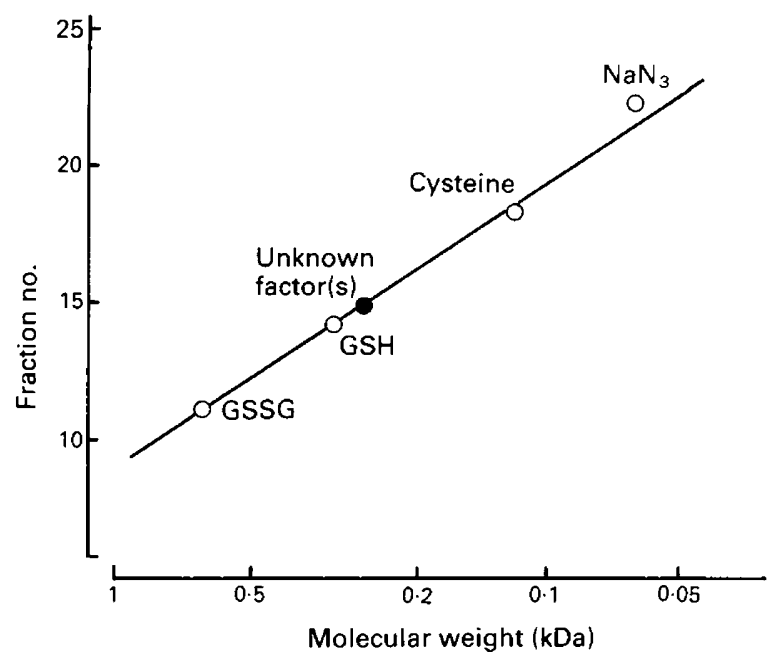

Fig. 3. A plot of the relationship between fraction number and log molecular weight. The conditions for elution were as in Fig. 2.

\section{Effects of test fluids on the oxygen consumption, lipid peroxide production and LDH leakage of fowl spermatozoa}

The initial rate of oxygen consumption of spermatozoa incubated in this fraction (fraction no. $15)$ increased significantly $(P<0.05)$ compared with that of the fresh medium fraction (Table 1$)$. The formation of lipid peroxides by spermatozoa incubated for $6 \mathrm{~h}$ in the fresh medium fraction whether or not ascorbic acid had been added was slightly higher than in the conditioned medium fraction, but there was no significant difference. However, after $12 \mathrm{~h}$ incubation, the amount of 


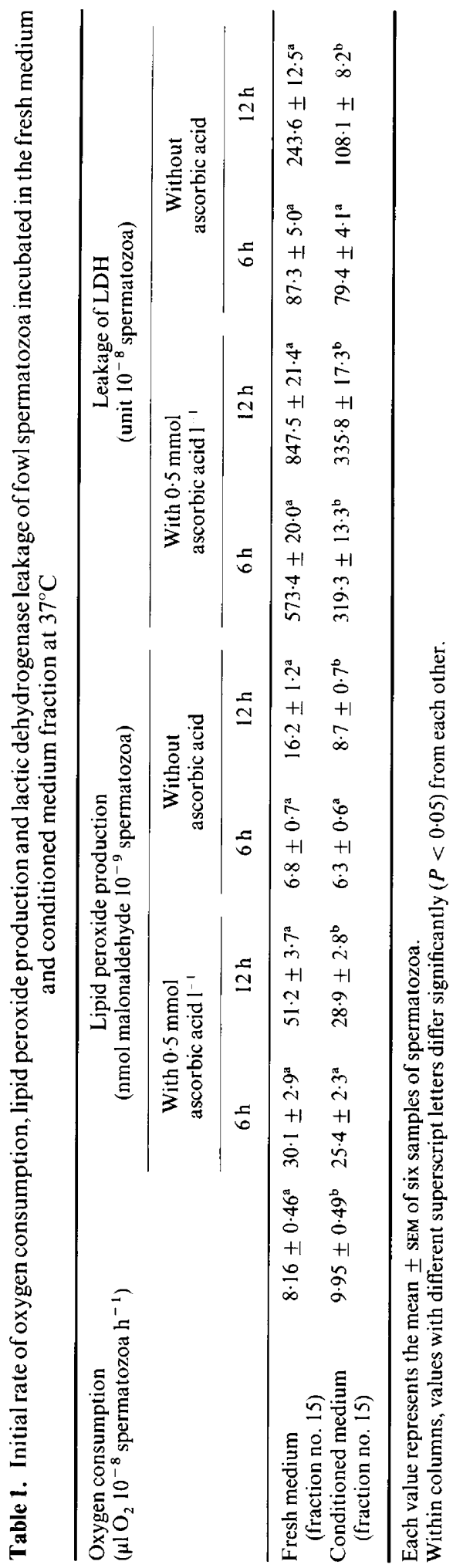


lipid peroxide of spermatozoa in the fresh medium fraction increased to around twofold compared with that in the conditioned medium fraction (Table 1). In addition to the lipid peroxide production, during $12 \mathrm{~h}$ incubation of spermatozoa, the release of sperm lactic dehydrogenase into the conditioned medium fraction was constantly lower than in those incubated in the corresponding fresh medium fraction (Table 1).

\section{Discussion}

The presence of various cultured cells greatly prolongs the maintenance of motility and fertilizing ability of fowl spermatozoa in vitro at $40-41^{\circ} \mathrm{C}$ (Ashizawa et al., 1976; Ashizawa \& Nishiyama, 1977, 1978; Fujihara \& Howarth, 1980; Ashizawa et al., 1982a, b). However, the mechanism(s) by which the cultured cells exerts a favourable effect on the maintenance of motility of fowl spermatozoa is still unknown, although there are several possibilities. One possibility is that a motility-prolonging factor(s) is provided by living cultured cells and that it diffuses or is secreted into the medium (Ashizawa \& Nishiyama, 1978; Fujihara \& Howarth, 1980; Ashizawa et al., 1983b). The other possibility is the presence of a 'sweeping' action in which 'toxic' products of sperm metabolism are scavenged by the cultured cells. In this study, it has been shown that when conditioned medium was separated into filtrate and residue by ultrafiltration, the filtrate prolonged motility of fowl spermatozoa compared with the control (filtrate of fresh medium). However, the residue of conditioned medium was only slightly more effective than its control (residue of fresh medium). This implies that the cultured fluid contains a secretory product(s) that can prolong the motility of fowl spermatozoa, and suggests that the main effective factor(s) prolonging sperm motility is a substance(s) of low molecular weight $(<20 \mathrm{kDa})$. From the gel filtration results, the effective factor might have a molecular weight of about $0.3 \mathrm{kDa}$.

It has been hypothesized that the prolonged motility of spermatozoa may be due to inhibition of sperm metabolism (Salisbury \& Lodge, 1962; Mann, 1964). We suspected that if there was an effective factor(s) for prolonging the motility, then it was likely to be involved in the inhibition of sperm metabolism. However, when fowl spermatozoa were suspended in the fractionated fluid including the effective factor, the initial rate of oxygen consumption increased significantly $(P<0.05)$ compared with that in the fresh medium (Table 1). Thus, the action of the effective factor does not appear to involve inhibition of fowl sperm metabolism.

However, both the formation of lipid peroxide and the leakage of LDH of fowl spermatozoa were inhibited in the conditioned medium compared with those in the fresh medium (Table 1). Fowl spermatozoa produce lipid peroxides when incubated aerobically at $40-41^{\circ} \mathrm{C}$ (Fujihara \& Howarth, 1978) and the formation of these products is associated with a dramatic fall in motility (Fujihara \& Howarth, 1978) and fertilizing ability (Wishart, 1984). Alvarez \& Storey (1982) also reported a close linear relationship between decline of rabbit sperm motility and extent of lipid peroxidation, as measured by malondialdehyde production. Furthermore, taurine, hypotaurine and adrenaline, which are low molecular weight substances, inhibit lipid peroxidation in rabbit spermatozoa and protect against loss of motility (Alvarez \& Storey, 1983). It is uncertain whether the factor prolonging fowl sperm motility in our experiment belongs to this category, but the effect could be a result of inhibition of lipid peroxidation, and the process of sperm membrane deterioration might be slowed down.

We thank G. J. Wishart, Dundee Institute of Technology, UK, for kindly reading the manuscript. This study was supported by a grant from the Ministry of Education, Science and Culture, Japan.

\section{References}

Alvarez, J.G. \& Storey, B.T. (1982) Spontaneous lipid peroxidation in rabbit epididymal spermatozoa: its effect on sperm motility. Biology of Reproduction 27, [102-1108. 
Alvarez, J.G. \& Storey, B.T. (1983) Taurine, hypotaurine, epinephrine and albumin inhibit lipid peroxidation in rabbit spermatozoa and protect against loss of motility. Biology of Reproduction 29, 548-555.

Ashizawa, K. \& Nishiyama, H. (1977) Effects of various cultured cells on the survival and fertilizing ability of fowl spermatozoa. Journal of Reproduction and Fertility 49, 405 407.

Ashizawa, K. \& Nishiyama, H. (1978) Effects of proximity of spermatozoa to cultured cells on the survival of fowl spermatozoa in vitro. Japanese Poultry Science 15, 74-77.

Ashizawa, K., Nishiyama, H. \& Nagae, T. (1976) Effects of oviducal cells on the survival and fertilizing ability of fowl spermatozod. Journal of Reproduction and Fertility 47, 305-311.

Ashizawa, K., Okauchi, K. \& Nishiyama, H. (1982a) Effects of distance between spermatozoa and oviducal or kidney tissues in explant culture on the survival of fowl spermatozoa. Japanese Journal of Zootechnical Science 53, 507-509.

Ashizawa, K., Tokudome, Y., Okauchi, K. \& Nishiyama, H. (1982b) Effects of HeLa ad BHK-21 cells on the survival of fowl, bull, ram and boar spermatozoa in vitro. Journal of Reproduction and Fertility 66, $663-666$.

Ashizawa, K., Nishiyama, H. \& Okauchi, K. (1983a) Prolonged survival of fowl, bull, and ram spermatozoa in the presence of somatic cultured cells in vitro. Proceedings of the 5th World Conference on Animal Production, Tokyo 2, $177 \cdot 178$.

Ashizawa, K., Chuman, K., Okauchi, K. \& Nishiyama, H. (1983b) The importance of survival of oviducal cells for prolonged viability of fowl spermatozoa. Japanese Journal of Zootechnical Science 54, 679684.

Barber, A.A. \& Bernheim, F. (1967) Lipid peroxidation: its measurement, occurrence and significance in animal tissue. Advances in Gerontology Research 2, 355-403.
Fujihara, N. \& Howarth, B., Jr (1978) Lipid peroxidation in fowl spermatozoa. Poultry Science 57, 1766-1768.

Fujihara, N. \& Howarth, B., Jr (1980) Prolonged survival of cock spermatozoa in vitro with fluid removed from tissue cultured oviducal cells. Poultry' Science 59, 164-167.

Fujihara, N. \& Koga, O. (1982) Factor(s) influencing the survival of cock spermatozoa in vitro. Canadian Journal of Animal Science 62, 951-953.

Fujihara, N., Tanaka, K. \& Nishiyama, H. (1973) In vitro fertilization of fowl ova. Japanese Journal of Zootechnical Science 44, 564-568.

Kielley, W.W. (1963) Preparation and assay of phosphorylating submitochondrial particles: sonicated mitochondria. Methods in Enzymology 6, 272277.

Mann, T. (1964) Influence of ion concentration, dilution, temperature, and other extraneous factors, on semen in vitro. In The Biochemistry of Semen and of the Male Reproductive Tract, pp. 339-364. Methuen, London.

Salisbury, G.W. \& Lodge, J.R. (1962) Metabolism of spermatozoa. Advances in Enzlmology 24, 35-104.

Schindler, H., Weinstein, S., Moses, E. \& Gabriel, I. (I955) The effect of various diluents and storage times on the fertilizing capacity of cock semen. Poultry Science 34, $1113-1117$.

Wheeler, N.C. \& Andrews, F.N. (1943) The influence of season on semen production in the domestic fowl. Poultry Science 22, $361-367$.

Wishart, G.J. (1984) Effects of lipid peroxide formation in fowl semen on sperm motility, ATP content and fertilizing ability. Journal of Reproduction and Fertility 71, 113-118.

Wishart, G.J. \& Ross, F.H. (1985) Characterisation of a spectrophotometric technique for the estimation of fowl and turkey sperm motility. Gamete Research 11, I69 178

Wróblewski, F. \& LaDue, J.S. (1955) Lactic dehydrogenase activity in blood. Proceedings of the Society of Experimental Biology and Medicine 90, 210-213.

Received 20 May 1991 